\title{
Anatomic All-Inside Anterior Cruciate Ligament Reconstruction Using the TransLateral Technique
}

\author{
Octav Russu1, Tiberiu Bățagă1, Marcela Todoran1, Emilian Ciorcila1, Teodora Maria Denisa Popa1, \\ Andrei-Marian Feier1, Radu Prejbeanu², Radu Fleaca ${ }^{3}$, Mihai Roman³, Tudor Sorin Pop', István Gergely \\ 1 University of Medicine and Pharmacy, Tîrgu Mureș, Romania \\ 2 "Victor Babeș" University of Medicine and Pharmacy, Timișoara, Romania \\ 3 "Victor Papillan" Faculty of Medicine, "Lucian Blaga” University, Sibiu, Romania
}

\section{CORRESPONDENCE \\ Andrei-Marian Feier Str. Gheorghe Marinescu nr. 38 540139 Tîrgu Mureș, Romania \\ Tel: +40 747501392 \\ E-mail: andreifeier@gmx.com}

\section{ARTICLE HISTORY}

Received: April 24, 2017

Accepted: May 13, 2017

Octav Russu • Str. Gheorghe Marinescu nr. 38 , 540139 Tîrgu Mures, Romania. Tel: +40 265215551 E-mail: octav@genunchi.ro

Tiberiu Bățagă • Str. Gheorghe Marinescu nr. 38 540139 Tîrgu Mureș, Romania, E-mail: tbataga@ gmail.com

Marcela Todoran - Str. Gheorghe Marinescu nr. 38 540139 Tîrgu Mureș, Romania. Tel: +40 740819718. E-mail: nuby09_03@yahoo.com

Emilian Ciorcila • Str. Gheorghe Marinescu nr. 38, 540139 Tîrgu Mureș, Romania. Tel: +40 749812395 E-mail: emilian.ciorcila@yahoo.com

Teodora Maria Denisa Popa • Str. Gheorghe

Marinescu nr. 38, 540139 Tîrgu Mureș, Romania. Tel: +40 751325 029. E-mail: teodoramariadenisa_popa@ yahoo.com

Radu Prejbeanu • P-ța Eftimie Murgu nr. 2, 300041 Timișoara, Romania. Tel: +40 256204 400. E-mail: raduprejbeanu@gmail.com

Radu Fleaca • Str. Lucian Blaga nr. 2A, 550169 Sibiu, Romania. Tel: +40 269212 320. E-mail: rfleaca@ yahoo.com

Mihai Roman • Str. Lucian Blaga nr. 2A, 550169 Sibiu, Romania. Tel: +40 269212 320. E-mail:

mihaidanroman@yahoo.com

Tudor Sorin Pop - Str. Gheorghe Marinescu nr. 38 540139 Tîrgu Mures, Romania. Tel: +40 265215551 E-mail: sorintpop@yahoo.com

István Gergely • Str. Gheorghe Marinescu nr. 38 540139 Tîrgu Mures, Romania. Tel: +40 265215551. E-mail: gergelyistvan@studium.ro

\begin{abstract}
Background: Anterior cruciate ligament (ACL) reconstruction is a commonly performed procedure and considered to be the gold standard in restoring knee function and stability in ACL-deficient knees. The TransLateral all-inside technique implies the use of only two portals - anterolateral and anteromedial, without the use of an accessory portal. The work is done using the lateral portal, while the medial portal serves as a viewing site. Only a few studies have been published regarding the assessment of the functional and clinical outcomes of this novel technique. Aim of the study: To determine the clinical effectiveness of the TransLateral procedure used for $\mathrm{ACL}$ reconstruction and its ability to re-establish joint functionality and stability in ACL-deficient knees. Material and methods: A prospective study was conducted at the Orthopedics and Traumatology Clinic no. 2 in Tîrgu Mureș. Thirty-two patients matched our inclusion criteria and were operated using the TransLateral technique for $\mathrm{ACL}$ reconstruction. Outcome assessment was performed using the Knee injury and Osteoarthritis Outcome Score (KOOS), the Lysholm score and the Tegner Activity Scale. The questionnaires include items referring to pain, physical functioning, sports activities, and quality of life. Operative time and ACL graft size were also documented. Results: All patients underwent single-bundle ACL restoration using a quadrupled semitendinosus tendon. Out of 32 patients, 21 had associated meniscus lesions and 8 collateral ligament injuries. Mean graft diameter was $8.7 \mathrm{~mm}$ and mean length $63.2 \mathrm{~mm}$. Significantly improved KOOS values were found at 12 months post-surgery regarding the mean baseline score: $59.3 \pm 5.3$ vs. $95.3 \pm 4.9, p<0.0001$. The Lysholm score improved from a mean of $56.3 \pm 4.9$ to $93.9 \pm 5.6, p<0.0001$ at the end-point. The Tegner activity scale ranged from $3.8 \pm 1.9$ to $5.9 \pm$ 2.4, $\mathrm{p}<0.0001$ at the final follow-up. Conclusions: The TransLateral technique proved its clinical effectiveness and its ability to restore knee stability after ACL reconstruction surgery.
\end{abstract}

Keywords: TransLateral, all-inside, anterior cruciate ligament

\section{INTRODUCTION}

Anterior cruciate ligament (ACL) reconstructions (ACLR) are the most frequent surgical interventions related to sports injuries worldwide. The incidence of ACL ruptures was 30 cases/100,000 individuals in 2008, the number of re- 
ported cases increasing every year.1 One of the fundamental principles in orthopedics is restoring the functional anatomy of the affected structure. As it has an insignificant healing capability, arthroscopic reconstruction of the ACL is the gold standard technique in active individuals who decide to continue sports and athletic activities.2-4 Several innovative techniques sought to provide elite outcomes after the reconstruction with fewer invasive drills, less complications on the long run, and shorter post-operative rehabilitation time.5-9 One of the classic and most frequently used techniques implies the usage of transtibial drilling in order to create the femoral tunnel. Therefore, the placement of the femoral tunnel depends crucially on the position of the transtibial drill, and a vertical malposition of the femoral tunnel can occur.10 Even with positive reported outcomes, this technique is not considered to entirely restore the anatomic position of the native ACL.11 A new concept frequently referred to as "anatomic" reconstruction of the ACL has been described in the literature, and biomechanical outcomes proved its superiority compared to non-anatomic reconstructions.12-15 The anatomic technique implies the use of a medial accessory portal through which the femoral tunnel is prepared.16 The technique is correlated with reduced surgical invasion and pain, earlier recovery after the reconstruction, shorter hospitalization times, and better cosmetic outcomes due to fewer incisions.17-20

Our objective was to determine the clinical effectiveness of the TransLateral technique used for ACL reconstruction and its ability to restore joint functionality and stability in ACL-deficient knees.

\section{MATERIALS AND METHODS}

A prospective, single-center study was carried out in the Orthopedics and Traumatology Department no. 2 in Tîrgu Mureș, Romanian between August 2015 and September 2016. All patients who presented to the outpatient clinic with an ACL-deficient knee were screened for inclusion in the study. Each patient was informed regarding the pros and cons of the available techniques. Out of 43 patients screened for inclusion, 32 opted for the all-inside technique using semitendinosus tendon as a graft for the new ligament. Exclusion criteria involved: multi-ligament injuries, revision cases, chondral or subchondral lesions higher than grade 2 Outerbridge classification, and patients aged under 16 years, where bone maturity is not complete.17 Each patient was operated by the same surgical team that had a two-year experience with the technique. The minimum follow-up period was set at 12 months. There were two scheduled follow-ups, at 6 and 12 months post-operative.

\section{Brief description of the TransLateral technique}

In order to work around the distal segment of the lateral condyle of the femur, laterally and to avoid the impingement on the patella tendon medially, special instruments are needed that were described by Logan et al. These include: an Opes radiofrequency probe (Arthrex Ltd, Naples, Florida, USA) used for soft tissue debridement; a curved marking/measuring equipment and an anatomical aiming arm for a retrograde drill; and a FlipCutter Arthrex. The patient is in supine position with a tourniquet applied through the intervention. Compared to the classical technique, the anterolateral portal is slightly lower and more medially. The anteromedial portal is usually created the traditional way or slightly lower. Arthroscopic evaluation and semitendinosus harvest and preparation are completed using the conventional method. The Opes radiofrequency probe is used for optimal debridement and grounding of the native ACL footprint after anatomic landmarks are identified. Two measurements are made afterwards, and using the device's sharp points, the femoral tunnel placement is established. The FlipCutter equipment is introduced within the lateral portal at the anatomical origin of the femur. An outside-in drilling is subsequently performed with the knee at $90^{\circ}$ of flexion antero- and retrograde. Next, the graft is inserted and fixed with a TightRope Arthrex on the femoral side and a bioresorbable screw on the tibial part.21

\section{Outcome evaluation tools}

Using a simple questionnaire, demographic data was collected by a study nurse at the time of enrolment. Operative time, ACL graft size and range of motion were documented. Anterior knee laxity was measured in $25^{\circ}$ of flexion using a RolimeterTM, Aircast ${ }^{ø}$ compact arthrometer. Patient-reported evaluation tools included the Knee Injury and Osteoarthritis Outcome Score (KOOS), the Lysholm score and the Tegner Activity Scale. KOOS was created with the purpose of evaluating short- and long-term symptoms and function in individuals with knee injury and osteoarthritis.22 It has five separate subscales with 42 items in total: a) pain, b) other symptoms, c) function in daily living, d) function in sport and recreation, and e) knee-related quality of life. The score is a percentage score ranging from 0 to 100,0 representing severe problems and 100 representing no difficulties. The Lysholm Score is regularly applied 
TABLE 1. Demographic characteristics

\begin{tabular}{lc}
\hline Variable & Value \\
\hline Age, mean $\pm \mathrm{SD}, \mathrm{y}$ & $29.1 \pm 7.6$ \\
$\mathrm{BMI}$, mean $\pm \mathrm{SD}$ & $25.2 \pm 4.2$ \\
Gender, male/female, $\mathrm{n}$ & $21 / 11$ \\
Time from injury to surgery, mo, mean $\pm \mathrm{SD}$ & $13 \pm 23.2$ \\
Follow-up period, mo, mean & 13.1 \\
Cartilage defects Outerbridge I/II, $\mathrm{n}$ & 11 \\
Associated meniscus lesions, $\mathrm{n}$ & \\
$\quad$ Lateral & 8 \\
$\quad$ Medial & 13 \\
Associated collateral ligaments injury, $\mathrm{n}$ & \\
$\quad$ Lateral & 1 \\
$\quad$ Medial & 7 \\
\hline
\end{tabular}

to assess the results of knee ligament operations. The current version contains 8 subscales: limp, support, locking, instability, pain, swelling, stair climbing, and squatting. Values from each subscale are summed in order to provide a total normalized score. The score varies from 0 to 100 , a higher value representing an improved outcome: excellent 95-100; good 84-94; fair 65-83; poor <64. The Tegner Activity Scale seeks to offer a standardized system of grading functional daily and sports activities. It is frequently used in combination with the Lysholm Score to evaluate subjects with ACL injuries and reconstructions. 23 A score of 0 is equivalent to retirement or disability due to knee-related injuries, while a score of 10 corresponds to involvement in elite competitive athletic activities.

\section{Statistical analysis}

Statistical analysis was used to compare outcomes for every follow-up stage before the surgery and at 6 and 12 months after surgery. Differences between the scores were analyzed using chi-square, t-test and one-way repeated ANOVA. The statistical significance was set at an alpha coefficient of 0.05 . All calculations were performed using
TABLE 2. Range of motion and knee laxity results

\begin{tabular}{lccc}
\hline & Extension* & Flexion & Laxity** $^{*}$ \\
\hline Preoperative, mean & $-0.9^{\circ}$ & $133.2^{\circ}$ & 10.9 \\
6 months, mean & $1.4^{\circ}$ & $136.9^{\circ}$ & 6.2 \\
12 months, mean & $0.5^{\circ}$ & $139.1^{\circ}$ & 6.2 \\
\hline
\end{tabular}

*negative value represents hyperextension beyond the $0^{\circ}$ point **values reported in millimeters

GraphPad InStat (GraphPad, San Diego, USA) and EpiInfo v. 7.1.4.0 (Centers for Disease Control and Prevention, Atlanta, USA).

\section{RESULTS}

The expected follow-up time was reached for each patient without any graft rupture during the one-year follow-up. There were no major postoperative complications, except a case with a small infection on the anteromedial portal incision. Out of 21 patients who had meniscus-associated lesions, 14 were repaired with a standard meniscal all-inside suture. Other demographic characteristics are presented in Table 1.

Mean operative time tourniquet time was 74.1 minutes (range 43-111 minutes) after sterile surgical dressings were applied. The mechanism of injury occurred during athletic activities in 17 (53\%) patients, with a valgus-twisting deceleration movement reported in 9 out of 17 cases. Concomitant injuries involved meniscus lesions in 21 $(66 \%)$ cases, collateral ligament injuries in $8(25 \%)$ cases, and cartilage defects in $11(34 \%)$ cases.

The mean graft diameter was $8.7 \mathrm{~mm}$ and mean graft length was $63.2 \mathrm{~mm}$ (range $54-70 \mathrm{~mm}$ ). Range of motion was measured for both injured and uninjured knees before and after surgery. There were no differences in extension or flexion between the injured and uninjured knees before the surgery. Table 2 includes mean flexion-extension results and anterior knee laxity for each follow-up.

TABLE 3. Outcomes from the KOOS*, Lysholm score and Tegner Activity Scale

\begin{tabular}{lcccc}
\hline & $\begin{array}{c}\text { Preoperative, } \\
\text { mean } \pm \text { SD }\end{array}$ & $\begin{array}{c}\mathbf{6} \text { months, } \\
\text { mean } \pm \text { SD }\end{array}$ & $\begin{array}{c}\text { 12 months, } \\
\text { mean } \pm \text { SD }\end{array}$ & P value** \\
\hline KOOS & $59.3 \pm 5.3$ & $74.6 \pm 11.1$ & $95.3 \pm 4.9$ & $<0.0001$ \\
Lysholm score & $56.3 \pm 4.9$ & $72.6 \pm 9.8$ & $93.9 \pm 5.6$ & $<0.0001$ \\
Tegner Activity Scale & $3.8 \pm 1.9$ & $5.8 \pm 1.1$ & $5.9 \pm 2.4$ & $<0.0001$ \\
\hline
\end{tabular}


Subjective outcomes from the KOOS, Lysholm score and Tegner Activity Scale for each follow-up are presented in Table 3. The KOOS score improved significantly at 6 months after reconstruction ( $\mathrm{p}<0.0001)$. The Lysholm score and Tegner Activity Scale also improved significantly from baseline preoperative scores at six months post-surgery. At the conventional radiograph follow-up, TightRope button positioning was precise in all patients. No differences in regards to KOOS, Lysholm score and Tegner Activity Scale were present in patients with associated lesions added to the ruptured ACL.

\section{DISCUSSIONS}

The all-inside technique has been used for ACL reconstruction for several years, but its clinical and functional effectiveness has not yet been rigorously evaluated. The key finding of our study is that the TransLateral all-inside anatomic reconstruction was able to provide stability to the affected knee 6 months post-surgery. Pain and function were two major outcomes to be evaluated, and the technique provided remarkable results. No complications and limitations regarding range of motion or joint functionality were documented. Subjective evaluation tools such as the KOOS, Lysholm score and Tegner Activity Scale improved significantly, even after six months post-reconstruction.

In a two-year follow-up trial using the TransLateral technique on 108 subjects, Yasen et al. concluded that this technique demonstrated good mid-term subjective and objective outcomes.15 Another trial on 92 individuals using the all-inside technique sought to prove its clinical effectiveness and functional efficacy.24 The Visual Analog Scale was used to evaluate subjective pain intensity and there were significant changes at 24 months of follow-up compared to baseline ( 5 vs. $0.1, \mathrm{p}<0.0001$ ). The Lysholm Score was 53.4 at baseline vs. 91.1 at 12 months $(\mathrm{p}<0.0001)$, and the Tegner Activity Scale was 2 at baseline vs. 5.5 at 12 months ( $\mathrm{p}<0.0001$ ), thus showing similar results to ours at one year post-reconstruction.

Classic transtibial drilling may be associated with nonanatomic positioning of the reconstructed graft, and the vertical femoral tunnel settlement may result in residual rotational knee instability.25,26 The TransLateral technique has the advantage of offering a better and more accurate femoral socket placement, by providing a clear view of the lateral condyle of the femur using the medial portal whilst operating from the lateral side.15 Additionally, it has been proven that drilling the femoral tunnel through a transtibial approach drives surgeons to have a tendency of drilling the tibial tunnel more posteriorly in order to have a precise placement on the femoral tunnel.27,28 Transportal drilling is therefore considered superior by allowing the operator to independently place and drill the femoral tunnel. Based on our results, we support this statement.

A recently published randomized controlled trial showed that the all-inside technique has less postoperative pain and rescue analgesics usage compared to other conventional techniques to date.29 Another randomized trial compared the outcomes of standard ACL reconstruction and all-inside technique.30 The subjective outcomes were similar, with no differences between the two techniques. However, pain after the first day of surgery was significantly lower in the all-inside group. The TransLateral technique also has the important advantage of preserving the gracilis muscle tendon, therefore protecting the hamstring strength and reducing postoperative rehabilitation time.31

There are some limitations to this study that should be mentioned. The use of a control study lot might bring a greater impact to the results and better potential recommendations. Also, the sample of patients might be considered too small compared to other published trials. Including patients with associated lesions added to ACL rupture may also incorporate biases, but an isolated rupture is considered rare. Another limitation is the absence of subjective pain assessment that could otherwise convey a different approach to the reported outcomes.

\section{CONCLUSION}

The TransLateral technique proved to be effective in restoring instability in ACL-deficient knees at one year post-reconstruction. Functional and clinical evaluation has shown promising results with accelerated rehabilitation, no range of motion limitation, and overall confident outcomes. When using this technique, all the work is performed within the lateral portal, while all the viewing is completed with no obstruction through the medial portal.

\section{CONFLICT OF INTEREST}

Nothing to declare.

\section{REFERENCES}

1. Csintalan RP, Inacio MC, Funahashi TT. Incidence rate of anterior cruciate ligament reconstructions. Perm J. 2008;123:17-21.

2. Bernardino S. ACL prosthesis: any promise for the future? Knee Surg Sports Traumatol Arthrosc. 2010;186:797-804

3. Shafizadeh S, Schneider MM, Bouillon B. Injuries of the anterior cruciate ligament in athletes. Chirurg. 2014;8510:888-894.

4. Chechik O, Amar E, Khashan M, Lador R, Eyal G, et al. An internationa survey on anterior cruciate ligament reconstruction practices. Int Orthop. 2013;372:201-206. 
5. Niki Y, Matsumoto H, Hakozaki A, et al. Anatomic double-bundle anterior cruciate ligament reconstruction using bone-patellar tendon-bone and gracilis tendon graft: a comparative study with 2-year follow-up results of semitendinosus tendon grafts alone or semitendinosus-gracilis tendon grafts. Arthroscopy. 2011;279:1242-1251.

6. Xie X, Liu X, Chen Z, Yu Y, Peng S, et al. A meta-analysis of bone-patellar tendon-bone autograft versus four-strand hamstring tendon autograft for anterior cruciate ligament reconstruction. Knee. 2015;222:100-110.

7. Wagner M, Kääb MJ, Schallock J, Haas NP, Weiler A. Hamstring tendon versus patellar tendon anterior cruciate ligament reconstruction using biodegradable interference fit fixation: a prospective matched-group analysis. Am J Sports Med. 2005;339:1327-1336.

8. Dejour D, Vanconcelos W, Bonin N, Saggin PR. Comparative study between mono-bundle bone-patellar tendon-bone, double-bundle hamstring and mono-bundle bone-patellar tendon-bone combined with a modified Lemaire extra-articular procedure in anterior cruciate ligament reconstruction. Int Orthop. 2013;372:193-199.

9. Middleton KK, Hamilton T, Irrgang JJ, Karlsson J, Harner CD. Anatomic anterior cruciate ligament $\mathrm{ACL}$ reconstruction: a global perspective. Part 1. Knee Surg Sports Traumatol Arthrosc. 2014;227:1467-1482.

10. Takahashi T, Takeda H, Watanabe S, Yamamoto H. Laser-guided placement of the tibial guide in the transtibial technique for anterior cruciate ligament reconstruction. Arthroscopy. 2009;252:212-214.

11. Steiner ME, Battaglia TC, Heming JF, Rand JD, Festa A, et al. Independent drilling outperforms conventional transtibial drilling in anterior cruciate ligament reconstruction. Am J Sports Med. 2009;3710:1912-1919.

12. Kondo E, Merican AM, Yasuda K, Amis AA. Biomechanical comparison of anatomic double-bundle, anatomic single-bundle, and nonanatomic single-bundle anterior cruciate ligament reconstructions. Am J Sports Med. 2011;392:279-288.

13. Nikolaou VS, Efstathopoulos N, Sourlas I, Pilichou A, Papachristou G. Anatomic double-bundle versus single-bundle $A C L$ reconstruction: a comparative biomechanical study in rabbits. Knee Surg Sports Traumatol Arthrosc. 2009;178:895-906.

14. van Eck CF, Lesniak BP, Schreiber VM, Fu FH. Anatomic single- and double-bundle anterior cruciate ligament reconstruction flowchart. Arthroscopy. 2010;262:258-268.

15. Yasen SK, Borton ZM, Eyre-Brook Al, et al. Clinical outcomes of anatomic, all-inside, anterior cruciate ligament $\mathrm{ACL}$ reconstruction. Knee. 2016;241:55-62

16. Cohen SB, Fu FH. Three-portal technique for anterior cruciate ligament reconstruction: use of a central medial portal. Arthroscopy. 2007;233:325. e1-e5.

17. Lubowitz JH, Ahmad CS, Anderson K. All-inside anterior cruciate ligament graft-link technique: Second-generation, no-incision anterior cruciate ligament reconstruction. Arthroscopy. 2011;27:717-727.

18. Kim SG, Kurosawa H, Sakuraba K, et al. Development and application of an inside-to-out drill bit for anterior cruciate ligament reconstruction. Arthroscopy. 2005;21:1012.
19. Smith P, Schwartzberg RS, Lubowitz JH. No tunnel 2-socket technique: All-inside anterior cruciate ligament double-bundle retroconstruction. Arthroscopy. 2008;24:1184-1189.

20. Barrett GR, Richardson K. Comparison of rear-entry two-incision and endoscopic techniques for reconstruction of the anterior cruciate ligament. J South Orthop Assoc. 1996:52:87-95.

21. Logan JS, Elliot RR, Wilson AJ. TransLateral ACL reconstruction: a technique for anatomic anterior cruciate ligament reconstruction. Knee Surg Sports Traumatol Arthrosc. 2012;207:1289-1292.

22. Roos EM, Lohmander LS. The Knee injury and Osteoarthritis Outcome Score KOOS: from joint injury to osteoarthritis. Health Qual Life Outcomes. 2003;1:64.

23. Collins NJ, Misra D, Felson DT, Crossley KM, Roos EM. Measures of knee function: International Knee Documentation Committee IKDC Subjective Knee Evaluation Form, Knee Injury and Osteoarthritis Outcome Score KOOS, Knee Injury and Osteoarthritis Outcome Score Physical Function Short Form KOOS-PS, Knee Outcome Survey Activities of Daily Living Scale KOS-ADL, Lysholm Knee Scoring Scale, Oxford Knee Score OKS, Western Ontario and McMaster Universities Osteoarthritis Index WOMAC, Activity Rating Scale ARS, and Tegner Activity Score TAS. Arthritis Care Res Hoboken. 2011;63Suppl11:S208-S228.

24. Schurz M, Tiefenboeck TM, Winnisch M, Syre S, Plachel F, et al. Clinical and Functional Outcome of All-Inside Anterior Cruciate Ligament Reconstruction at a Minimum of 2 Years' Follow-up. Arthroscopy. 2016;322:332-7.

25. Lee MC, Seong SC, Lee S, et al. Vertical femoral tunnel placement results in rotational knee laxity after anterior cruciate ligament reconstruction. Arthroscopy. 2007;23:771-778

26. Yau WP, Fok AW, Yee DK. Tunnel positions in transportal versus transtibial anterior cruciate ligament reconstruction: a case-control magnetic resonance imaging study. Arthroscopy. 2013;296:1047-1052.

27. Silva A, Sampaio R, Pinto E. ACL reconstruction: Comparison between transtibial and anteromedial portal techniques. Knee Surg Sports Traumatol Arthrosc. 2012;20: 896-903.

28. Kopf S, Forsythe B, Wong AK, et al. Non-anatomic tunnel position in traditional single-bundle anterior cruciate ligament reconstruction evaluated by three-dimensional computed tomography. J Bone Joint Surg Am. 2010;92:1427-1431.

29. Benea $H$, d'Astorg $H$, Klouche $S$, et al. Pain evaluation after all-inside anterior cruciate ligament reconstruction and short term functional results of a prospective randomized study. Knee. 2014;211:102-106.

30. Lubowitz JH, Schwartzberg R, Smith P. Randomized controlled trial comparing all- inside anterior cruciate ligament reconstruction technique with anterior cruciate ligament reconstruction with a full tibial tunnel. Arthroscopy. 2013;29:1195-1200.

31. Yosmaoglu HB, Baltaci G, Ozer H, Atay A. Effects of additional gracilis tendon harvest on muscle torque, motor coordination, and knee laxity in ACL reconstruction. Knee Surg Sports Traumatol Arthrosc. 2011:19:12871292. 